\title{
Gastrointestinal obstruction caused by solidification and coagulation of enteral nutrition: pathogenetic mechanisms and potential risk factors
}

This article was published in the following Dove Press journal: International Medical Case Reports Journal

\author{
Grazia Leonello,' Antonio \\ Giacomo Rizzo,' Viviane \\ Di Dio, ${ }^{2}$ Antonio Soriano, ${ }^{3}$ \\ Claudia Previti, ${ }^{3}$ Grazia \\ Giulia Pantè, ${ }^{3}$ Claudio \\ Mastrojeni,' Sebastiano \\ Pantè
}

'Department of Human Pathology of Adults and Evolutive Era "Gaetano Barresi", University of Messina, Messina, Italy; ${ }^{2}$ Health Research Institute Bonino Pulejo, Piemonte Hospital, Messina, Italy; ${ }^{3}$ Department of Medical and Surgery Science, University of Messina, Messina, Italy

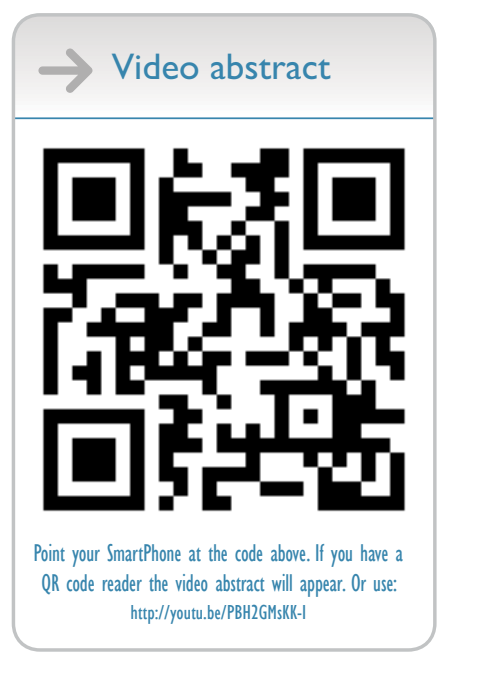

Correspondence: Antonio Giacomo Rizzo

Department of Human Pathology of Adults and Evolutive Era "Gaetano Barresi", University of Messina, Via Consolare Valeria, 98125 , Messina, Italy Tel +3909022I 7025 Fax +3909022I 3206 Email agrizzo@unime.it

\begin{abstract}
Enteral nutrition (EN) is preferred in order to provide nutrition and reduce catabolism in critically ill patients. Recent studies suggest that the use of EN is successful and complications are rare. However, an underestimated mechanical complication of tube feedings seen in critically ill patients is the coagulation and solidification of the EN causing gastrointestinal obstruction. This report describes two clinical cases ( $1.23 \%$ of all cases seen at our clinic) of obstruction and perforation of the small bowel secondary to the solidification of EN. The understanding and early recognition of this potential complication are essential for the prevention and successful treatment of this condition.
\end{abstract}

Keywords: enteral nutrition, gastrointestinal contents, intestinal obstruction, small-bowel bezoar

\section{Introduction}

Postoperative (postop) enteral nutrition (EN) via a gastric or jejunal feeding tube is widely employed and usually well tolerated in a critical patient with a functioning small bowel. ${ }^{1,2}$ Nowadays, EN is the method of choice in intensive care units (ICUs), as it is able to provide complete nutrition to critical patients in order to reduce catabolism, immune system suppression and septic complications. ${ }^{3,4}$ Functional intestinal complaints occur frequently, but generally respond to variations of the infusion rate or of the tube feeding formula.

An underestimated complication of tube feeding is the coagulation and solidification of EN in the gastrointestinal (GI) tract; this condition can elicit serious complications, such as mural abscess, ulcers, intestinal bleeding, pancreatitis, small-bowel obstruction and perforation. ${ }^{3}$

Occasionally, unspecific signs of intestinal disturbance may progress to a syndrome of abdominal distension, hypotension and hypovolemic shock, resulting in extensive small-bowel necrosis. ${ }^{2}$

In September 2013, a review article on PubMed database of reports published from 1948 to 2012 (keywords: GI obstruction, enteral nutrition, solidification, coagulation and bezoar) identified and summarized 33 articles reporting 58 cases of critically ill patients with GI obstruction due to solidification of EN. This complication was localized in the esophagus in 44 patients, in the stomach in one and in the small intestine in 13. In particular, 12 patients out of 17 undergoing EN via a feeding tube jejunostomy developed obstruction of the small bowel; in the other five cases, the obstruction occurred in the esophagus, probably related to intragastric dislocation of the jejunal tube. Most patients were mechanically ventilated, had undergone an upper 
GI surgery and/or received drugs that could have caused GI motility disorders. The record chart of 162 patients who, over a 5-year period (2007-2012), received EN via jejunal tube feeding was reviewed, in order to assess the incidence of mechanical complication due to tube feedings. Two patients (1.23\%) who showed a clinical picture of obstruction and perforation of the small bowel secondary to solidification of EN were found. The peculiar aspects of the clinical course found in these patients were evaluated and compared with the previous findings of small-bowel obstruction due to the solidification of EN reported in the literature.

\section{Case reports Case I}

A 59-year-old man was admitted to our hospital with a history of nausea, asthenia, reduced food ingestion, weight loss ( $5 \mathrm{~kg}$ in 2 months), episodes of alimentary emesis and melena. On examining past medical history, a myocardial ischemia with placement of coronary stent (7 years ago), a hypertensive cardiopathy under treatment with dicumarol and an exertional dyspnea were detailed. Spirometry showed a mild grade airway obstructive syndrome. Cardiac examination showed a sinus rhythm ( 80 beats/min), signs of inferior necrosis, depression of ST segment, sporadic supraventricular premature beats, arterial blood pressure of $170 / 80 \mathrm{mmHg}$, normal size of the left ventricle with hypertrophy of interventicular septum, slight mitral and tricuspid valve failure and good global function of the left ventricle (ejection fraction: 60\%). Tumor markers were also checked: carcinoembryonic antigen (CEA): 44.6 (normal range, 0-5 ng/mL), Ca 19.9: 4299 (normal range, 0-37 U/mL), Ca 125: 111.11 (normal range, 0-37 U/mL) and alpha-fetoprotein (AFP): 2.34 (normal range, 0-13.40 $\mathrm{ng} / \mathrm{mL}$ ). Staging computed tomography (CT) of the abdomen showed diffusely infiltrating pathologic tissue that permeated as a sleeve the gastric antrum. The patient underwent an upper GI endoscopy, which showed an ulcerated gastric carcinoma localized in the lower third of the gastric body and in the gastric antrum. Histologic examination of the biopsy revealed gastric adenocarcinoma, classified as diffuse type according to Lauren's criteria, with mucoid cells that often showed a signet ring appearance. Colonoscopy revealed a sessile polyp (size $9 \mathrm{~mm}$ ) in the cecum that was removed endoscopically; the histologic exam evidenced an infiltrative adenocarcinoma with mucoid cells that showed a signet ring appearance. The patient was operated on for the gastric neoplasia; the surgical exploration evidenced a hard tumor of the antrum, the presence of carcinosis on parietal peritoneum and on mesi and yellow abdominal fluid. The patient underwent an almost total gastric resection of the intestinal continuity according to Roux en Y; a feeding jejunostomy was performed with the insertion of a $70 \mathrm{~cm}$ tube below the jejuno-jejunal anastomosis. Histologic examination evidenced a gastric adenocarcinoma of diffuse type according to Lauren, with massive parietal infiltration "linitisplastica" (pT3N2M1). The postop course was regular and on the 4th postop day, with alvus free of gas, the EN $(20 \mathrm{~mL} / \mathrm{h}$ NUTRISON) was started. On the 7 th postop day, the presence of enteric juice $(1200 \mathrm{~mL}$ in the right and $400 \mathrm{~mL}$ in the left) was observed in two drainages. The radiologic study of superior digestive tract with "aqueous dye" evidenced a perianastomotic leakage of the gastro-digiunal anastomosis. The general condition of the patient rapidly worsened with appearance of anuria, hypotension $(80 / 40 \mathrm{mmHg})$ and reduced $\mathrm{O}_{2}$ saturation. An emergency laparotomy was performed, and occlusion of jejunal lumen $80 \mathrm{~cm}$ distal to the tube insertion, severe dilatation of the small bowel above, and jejunal wall bowel necrosis with perforation (of $2 \mathrm{~cm}$ ), and leakage of doughy and dense fluid were found. The fluid coming from the perforated jejunal bowl was drained with manual milking. No evidence of intestinal strangulation or arterial occlusion was found. The necrotic edges of the small-bowel perforation were resected and the surgical wound sutured. The dehiscence of gastro-jejuneal anastomosis (size $1 \mathrm{~cm}$ ) and of jejunumjejunal anastomosis (size $2 \mathrm{~cm}$ ) was repaired with Lambert stitches. At the end of the surgery, an abdominal cavity lavage was performed. The histopathology examination showed transmural necrosis of jejunal margins and EN compacted in the intestinal lumen. The patient was admitted to the ICU due to severe cardiorespiratory failure, where he died.

\section{Case 2}

A 79-year-old man was admitted to our hospital for asthenia, severe weight loss ( $20 \mathrm{~kg}$ in 6 months) and postprandial emesis. On examination of the past medical history, Wernicke encephalopathy, atrial fibrillation (under treatment with dicumarol), a severe diverticular disease of the colon and inferior myocardial ischemia were detailed. Tumor markers were tested: AFP 1.9 (0-13.40 ng/mL), Ca 19.9: 11.10 (normal range, 0-37 U/ $\mathrm{mL}$ ), $\mathrm{Ca}$ 125: 5.0 (normal range, $0-37 \mathrm{U} / \mathrm{mL}$ ) and $\mathrm{Ca}$ 15.3: 12.6 (normal range, 0-29 U/mL). Markers of iron metabolism were as follows: Vit B12: 252 (normal range, $240-850 \mu \mathrm{g} / 100$ $\mathrm{mL}$ ), folate 3.04 (normal range, $5-15 \mu \mathrm{g} / \mathrm{L}$ ), total protein 5.8 $\mathrm{g} / \mathrm{dL}$, albumin $2.26 \mathrm{~g} / \mathrm{dL}, \mathrm{A} / \mathrm{G}$ ratio 1.7. Cardiac examination evidenced complete arrhythmia from atrial fibrillation (74 beats/min); mild hypertrophy of interventricular septa, imbalanced conduction of right cardiac ramus, biatrial dilatation and good functioning of the left ventricle (ejection fraction: 
$52 \%$ ). The $\mathrm{CT}$ of the head did not show any areas of pathologic density in cerebral parenchyma, and showed normal volume of the ventricular system, and Mini Mental State Evaluation 22.04/30. Colonoscopy evidenced a severe diverticular disease with a pedunculated polyp in the sigma (size $12 \mathrm{~mm}$ ) that was endoscopically removed. Histologic examination evidenced a villous adenoma with areas of severe dysplasia. CT of the abdomen showed a gastric duodenal dilatation with the presence of a duodenal diverticulum near the ampulla of Vater (size $4 \mathrm{~cm}$ ), in the third portion of duodenum in front of the vena cava, and the presence of a lumen stenosis (length $3 \mathrm{~cm}$ ) with concentric morphology. On gastroduodenoscopy, a vegetant tumor narrowing the intestinal lumen at the level of the third portion of the duodenum was found. Histologic examination evidenced a tubule villous adenoma with severe dysplasia and areas of adenocarcinoma. Based on these findings, the patient underwent surgery for the resection of third and fourth segments of the duodenum and the first jejunal loop. A duodenumjejunostomy was tailored with a stapler. A feeding jejunostomy tube was placed $70 \mathrm{~cm}$ below the anastomosis.

Histologic examination performed from the intestinal resection showed a moderately differentiated adenocarcinoma of the duodenum with subsierosa infiltration, margins of the surgical resection free from neoplastic invasion and metastasis in $1 / 9$ nodes (pT3N1Mx). The postop period was regular and on day 4, the EN (NUTRISON $20 \mathrm{~mL} / \mathrm{h}$ ) was started, and on day 6 , the alvus was free of gas and stool.

On the 12th day postop, the patient complained of abdominal diffuse colic pain and fecaloid vomiting. An emergency laparotomy was performed and a jejunal perforation (size 3 $\mathrm{cm}$ ) on the antimesenteric intestinal wall, with leakage of doughy and dense, whitish and pasty fluid was found. The abdominal fluid was drained through manual milking.

The occlusive bezoar elicited also a visceral dilatation of $60 \mathrm{~cm}$ below the duodeno-jejunostomy; due to the presence of areas of transmural necrosis in this tract, a resection of $80 \mathrm{~cm}$ of the small bowel and an anastomosis jejuno-jejunal L-L jejunostomy with stapler were performed. Histologic examination showed severe edema, hyperemia and lymphatic stasis of the jejunal submucosa for $60 \mathrm{~cm}$ in length. The patient was admitted to the ICU due to severe cardiorespiratory failure, where he died.

\section{Ethics information}

The record chart study was given to the Ethics Committee of University Hospital Policlinico G. Martino Messina (Azienda Ospedaliera Universitaria Policlinico "G. Martino" Messina). According to the Italian Drug Agency (AIFA), as reported in "Determinazione 20 marzo 2008 - Linee guida per la classificazione e conduzione degli studi osservazionali sui farmaci", this study can be classified as a retrospective observational study and formal approval is not required. Patients provided written informed consent for the review of their medical records. Case report data were collected from patients who had provided the written informed consent for the treatment and publication of their case details.

\section{Discussion}

Nutritional support is recognized to play a leading role in minimizing postop morbidity and mortality. Nutrition delivered through the enteral route is widely preferred over that given parenterally, in order to maintain gut integrity and to prevent mucosal atrophy and bacterial translocation. ${ }^{5}$ Postsurgical critically ill and, especially, mechanically ventilated patients are frequent candidates for jejunal feeding. EN provides a complete nutrition with a low complication rate, good acceptance by the patient and favorable costeffectiveness. ${ }^{6-11}$ By delivering enteral feeding in the small bowel below the pylorus, the frequency of regurgitation and the risk of aspiration pneumonia are decreased. At the same time, nutrient intake is maximized with an increase in proteins and calories delivered and a shorter time to target the optimal dose of nutrition. ${ }^{12}$

In seven randomized trials, small-bowel versus gastric feedings were associated with a reduction in the incidence of pneumonia without any difference in morbidity and mortality. Strategies that increase EN support, minimizing the risks associated, improve the outcomes of critically ill patients. Delivery of nutrients into the small intestine, via a tailored jejunostomy, is effectively well tolerated by the majority of patients, but morbid complications have been described with increasing frequency. ${ }^{5}$ Solidification of EN in the GI tract was first reported in the literature in 1981. The postop EN may be sometimes responsible for a severe complication such as mesenteric ischemia. Small-bowel necrosis is rare, but can be a highly morbid complication related to postop jejunal feeding tube. The common clinical picture is that of a patient without significant risk factors for mesenteric ischemia who, during the early postop period, develops unspecific abdominal symptoms, rapidly progressing to septic shock and, eventually, multiple organ failure and death. Mesenteric ischemia may be present in up to $3.5 \%$ of enteral-fed surgical patients, and the associated mortality approaches $85 \%-100 \%$ of the patients. ${ }^{8}$ The lack of specific symptoms provides a high suspicion for the diagnosis and requires a prompt abdominal surgical exploration and bowel 
resection. The surgical approach can positively influence morbidity and mortality. ${ }^{8-10}$ Surgical exploration should be considered during the early stage to prevent fatal widespread bowel infarction. ${ }^{10}$ Cases of ileus bezoar after postop EN through a needle jejunostomy or a nasoduodenal tube have also been reported. Surgical exploration revealed a mechanical ileus caused by the coagulation and solidification of the nutrition formula distal to the catheter tip. Bezoar formation represents an underestimated complication of postop enteral feeding, but the pathogenesis still remains unclear. The acute onset of abdominal pain and the development of small-bowel obstruction, often with consequent mesenteric hemorrhages, are the main clinical symptoms of this severe complication. ${ }^{4,911}$ Bulk forming agents such as fibers may not be appropriate for every tube-fed patient; some enteral products may be contraindicated in particular types of patients. ${ }^{9}$ The obstruction of esophageal lumen due to the formation of a bezoar caused by the solidification of the enteral solution has also been observed, but medical and endoscopic treatments managed to solve the majority of the cases reported in the literature. ${ }^{4}$ Although delivery of nutrients into the small bowel is effectively well tolerated by a large number of patients, morbid complications have been observed with increased frequency. The two cases described in this report, who both underwent a major abdominal surgery due to malignancy (gastric and duodenal), received postop EN through a surgically placed jejunostomy tube. EN was started on the fourth day after surgery at a rate of $20 \mathrm{~mL} / \mathrm{h}$ (NUTRISON). At that time, the alvus was free from gas and stool. After 12 and 14 days postop, respectively, the two patients developed clinical signs of intestinal obstruction with rapid and severe deterioration of the vital parameters. The patients immediately underwent an emergency laparotomy; the coagulation and solidification of EN had caused jejunal bowel obstruction and perforation of antimesenteric wall of the small bowel, related to the development of transmural ischemic necrosis. The development of this complication had many similarities to necrotizing enterocolitis: hyperosmolarity, invasive bacterial overgrowth and massive bolus impaction are implicated in the genesis of direct mucosal injury and severe local vasospasm and could cause ischemic necrosis and perforation. ${ }^{13}$ The causative mechanism remains unclear, but it is most likely the result of several factors, both systemic and mechanical, responsible for the coagulation of enteral formula solution. ${ }^{2}$ Coagulating properties of EN are related to the composition of the mixture; lactobezoars occur with casein-predominant formulas. ${ }^{14}$ Surgery of the upper intestinal tract (gastrectomy, piloroplasty, Roux en $\mathrm{Y}$ anastomosis, Whipple procedure) is considered the most important risk factor because it determines changes in the anatomic structure and alterations of the neurohormonal functional mechanisms of the GI tract, especially regarding the secretion of digestive enzymes. Pancreatic surgery reduces the secretion of pancreatic enzymes, and vagotomy slows down the progression of indigestible solids and decreases hydrochloric acid secretion. In critically ill patients, splanchnic hypoperfusion due to a low cardiac state, shock, use of vasopressor and/or narcotics and imbalance of inflammatory cytokines predispose to solidification of EN. This condition of vascular hypoperfusion may lead to ischemia, reduced bicarbonate secretion, decreased upper GI motility and acid back diffusion. Dehydration is also considered a risk factor in patients with renal failure or with major burns. Some drugs that interfere with digestive enzymes may also contribute to the solidification of EN (antacid, H2 antagonist, and so on), while sucralfate may bind the components of EN to form insoluble complexes. Solidification of EN in the small bowel requires prompt treatment with an emergency laparotomy.

This uncommon life-threatening complication should be considered in patients with abdominal pain and distension, increased naso-gastric output and signs of intestinal ileus. In these patients, tube feeding should be immediately discontinued and total parenteral nutrition considered. Awareness of pathogenetic mechanisms and potential risk factors is the most important tool for preventing or early diagnosis of GI obstruction caused by solidification and coagulation of EN. In conclusion, bezoar formation represents an underestimated complication of postop enteral feedings. Acute onset of abdominal pain and the development of small-bowel obstruction are the main symptoms of this severe complication.

\section{Author contributions}

All authors contributed toward data analysis, drafting and revising the paper and agree to be accountable for all aspects of the work

\section{Disclosure}

The authors report no conflicts of interest in this work.

\section{References}

1. Halkic N, Guerid S, Blanchard A, Gintzbuerger D, Matter M. Smallbowel perforation: a consequence of feeding jejunostomy. Can J Surg. 2005;48(2):161-162.

2. Schun CD, Daly JM. Small bowel necrosis associated with postoperative jejunal tube feeding. J Am Coll Surg. 1995;180(4):410-416. 
3. Luttikhold J, van Norren K, Buijs N, Rijina H, van Leeuwen PAM. Gastrointestinal obstruction by solidification of enteral nutrition: a result of impaired digestion in critically ill patients. Nutr Ther Metabolism. 2013; 31(3):101-109.

4. Caldeira A, Casanova P, Sousa R, Martins P, Banhudo A, Pimentel J. Enteric nutrition and esophageal impactation: what relationship. Acta Med Port. 2010;23(2):183-190.

5. Rai J, Flint LM, Ferrara JJ. Small bowel necrosis in association with jejunostomy tube feedings. Am Surg. 1996;62(12):1050-1054.

6. Scaife CL, Saffle JR, Morris SE. Intestinal obstruction secondary to enteral feedings in burn trauma patients. JTrauma. 1999;47(5):859-863.

7. Staelens S, Van den Driessche M, Barclay D, et al. Gastric emptying in healthy newborns fed an intact protein formula, a partially and an extensively hydrolysed formula. Clin Nutr. 2008;27(2):264-268.

8. Melis M, Fichera A, Ferguson MK. Bowel necrosis associated with early jejunal tube feeding: a complication of postoperative enteral nutrition. Arch Surg. 2006;141(7):701-704.
9. Mclvor AC, Meguid MM, Curtas S, Warren J, Kaplan DS. Intestinal obstruction from cecal bezoar; a complication of fiber-containing tube feedings. Nutrition. 1990;6(1):115-117.

10. Sarap AN, Sarap MD, Childers J. Small bowel necrosis in association with jejunal tube feeding. JAAPA. 2010;23(11):2830-2832.

11. Dedes KJ, Schiesser M, Schafer M, Clavien PA. Postoperative bezoar ileus after early enteral feeding. J Gastrintest Surg. 2006;10(1):123-127.

12. Heyland DK, Drover JW, Dhaliwal R, Greenwood J. Optimizing the benefits ad minimizing the risk of enteral nutrition in the critically ill: role of small bowel. JPEN J Parenter Enteral Nutr. 2002;26(Suppl 6):S51-S57.

13. Lawlor DK, Inculet RI, Malthaber RA. Small-bowel necrosis associated with jejunal tube feeding. Can J Surg. 1998;41(6):459-462.

14. Schreiner RL, Brady MS, Ernst JA, Lemons JA. Lack of lactobezoars in infants given predominantly whey protein formulas. Am J Dis Child. $1982 ; 136(5): 437-439$.
International Medical Case Reports Journal

\section{Publish your work in this journal}

The International Medical Case Reports Journal is an international, peer-reviewed open-access journal publishing original case reports from all medical specialties. Previously unpublished medical posters are also accepted relating to any area of clinical or preclinical science. Submissions should not normally exceed 2,000 words or
Submit your manuscript here: https://www.dovepress.com/international-medical-case-reports-journal-journal

\section{Dovepress}

4 published pages including figures, diagrams and references. The manuscript management system is completely online and includes a very quick and fair peer-review system, which is all easy to use. Visit http://www.dovepress.com/testimonials.php to read real quotes from published authors. 